\title{
NEAR ZERO WASTE USING RECYCLED OF CRUSHED CONCRETE AGGREGATE IN ASPHALT MIXTURES
}

\author{
Farag Khodary ${ }^{1}$ \\ ${ }^{I}$ Civil Engineering Department, Qena Faculty of Engineering, South Valley University, Qena, Egypt
}

\begin{abstract}
In asphalt mixtures aggregate generally represents the largest proportion of asphalt concrete mixture. It accounts for 92 to 96 percent of asphalt concrete mixtures by weight or approximately 75 to $85 \%$ by volume. Using these large quantities of aggregates in asphalt mixtures affect the natural resources. So recycling of crushed concrete could be a solution to this problem. The use of recycled crushed concrete in asphalt mixtures can prevent the accumulation of waste material and primary production costs as well as environmental pollution. In this research the basic properties of natural aggregate and recycled aggregate were evaluated. In asphalt concrete mixtures natural aggregate replaced with recycled aggregate in deferent percentage namely 10\%, 20\%, 30\%, 40\% and 50\%. The mechanical characteristics of the mixtures were evaluated by Marshall Stiffness and indirect tensile strength to choose the optimum recycled aggregate replacement ratio. The results indicated that using recycled aggregate in asphalt concrete mixtures have good impact in environment protection and economics. Up to $20 \%$ of recycled of crushed concrete aggregate can be used in asphalt concrete mixtures. The mixtures with recycled of crushed concrete aggregate have low stiffens and stability so it should be used at low traffic area.
\end{abstract}

Keywords: Asphalt Mixtures, Environmental Pollution, Recycled of Crushed Concrete Aggregate, Marshall Stiffness

\section{INTRODUCTION}

In worldwide, the concrete industry is consuming 10 billion tons of sand and aggregate per year [1]. Using large amount of natural resources in the construction work was needed to be recycled into other materials suitable for use either in the same field or in another field. Nowadays recycling of concrete aggregate is very important subject endeavor for sustainable development which concern with environmental and economic issues [2,3]. Demolition of concrete structures produced large amounts of aggregate, which have bad impact of the environment. One of the important solution to this problem is using recycled of crushed concrete aggregate in asphalt mixtures. This race a question why recycling? Recycling can reduce the need for the burial of construction waste and the recycled aggregate is less expensive than natural aggregates. From the point of environmental protection using recycled aggregates can minimize environmental impact and reduce using of natural resources Concrete waste constitutes the major proportion of construction waste at about $50 \%$ of the total waste generated $[4,5]$. The volumetric properties of asphalt specimens containing recycled of crushed concrete aggregate were relatively lower compared with the values found for conventional asphalt concrete except the percentage of air voids [6,7]. The feasibility of partial substitution of granite aggregate in hot-mix asphalt with waste concrete aggregate was investigated and the result suggest feasible use of waste concrete as partial aggregate substitution in asphalt concrete mixtures[8,9]. Recycled fine aggregates powder was used in asphalt concrete mixtures. Recycled fine aggregates powder is a by-product of the production of recycled concrete aggregate which causes many serious environmental problems. The results indicate that Recycled fine aggregates powder can improve the properties of asphalt mixture, such as including water sensitivity and fatigue resistance. On the other hand recycled concrete aggregate cause a little decrease of the low-temperature performance. But from the total result of the research recycled concrete aggregate can be used in asphalt pavement, especially in hot regions. [10].

\section{MATERIALS}

\subsection{Aggregate}

Two type of aggregate were used in this research first is crushed limestone aggregate with specific gravity 2.76 and the second one is recycled aggregate. The recycled aggregate was obtained in the lab by churching of cement concrete then the resulted aggregate was washed and dried. The gradation of the recycled aggregate has been added to the asphalt mixtures according to the needed percentage. The properties of the used new aggregates and recycled aggregate are shown in Table (1), the Gradation of the total aggregates mix was obtained by sieve analysis according to the Egyptian Highway Standard Specification (4C). To obtain the required gradation $23 \%$ of coarse aggregate (a), $36 \%$ of coarse aggregate (b), $36 \%$ of fine aggregate, and $5 \%$ of filler, (by weight of total aggregate mix), are mixed together. The results of the total mix gradation are shown in Table (2) and Figure (1). 
Table 1 : Properties of Aggregate Materials.

\begin{tabular}{|l|c|c|c|}
\hline \multicolumn{1}{|c|}{ Test } & Results of new aggregate & Recycled aggregate & Spec. Limits \\
\hline Specific Gravity & 2.76 & 2.29 & $2.5 \sim 2.8$ \\
\hline Water absorption (\%) & 2.40 & 5.9 & $\leq 5$ \\
\hline Los Angeles Abrasion (\%) & 25 & 34 & $\leq 40$ \\
\hline
\end{tabular}

Table 2 : Gradation of the Aggregates and Filler.

\begin{tabular}{|c|c|c|c|c|c|c|c|c|c|c|c|}
\hline \multirow{2}{*}{$\begin{array}{l}\text { Sieve } \\
\text { size } \\
\text { "mm" }\end{array}$} & \multicolumn{2}{|c|}{ Agg.,(2) } & \multicolumn{2}{|c|}{ Agg.,(1) } & \multicolumn{2}{|c|}{ Sand } & \multicolumn{2}{|c|}{ Filler } & \multirow{2}{*}{$\begin{array}{l}\text { Total } \\
\text { Mix }\end{array}$} & \multicolumn{2}{|c|}{ Spec. Limits (4-c) } \\
\hline & $\% \mathrm{P}$ & $23 \%$ & $\% \mathrm{P}$ & $36 \%$ & $\% \mathrm{P}$ & $36 \%$ & $\% \mathrm{P}$ & $5 \%$ & & Lower & Upper \\
\hline 25 & 100 & 23 & 100 & 36 & 100 & 36 & 100 & 5 & 100.0 & 100 & 100 \\
\hline 19 & 91 & 20.93 & 100 & 36 & 100 & 36 & 100 & 5 & 97.93 & 80 & 100 \\
\hline 12.50 & 34 & 7.82 & 100 & 36 & 100 & 36 & 100 & 5 & 84.82 & 70 & 90 \\
\hline 9.50 & 3 & 0.69 & 83 & 29.88 & 100 & 36 & 100 & 5 & 71.57 & 60 & 80 \\
\hline 4.75 & & & 27 & 9.72 & 100 & 36 & 100 & 5 & 50.72 & 48 & 65 \\
\hline 2.36 & & & 3 & 1.08 & 91 & 32.76 & 100 & 5 & 38.84 & 35 & 50 \\
\hline 0.60 & & & 0.5 & 0.18 & 55 & 19.8 & 100 & 5 & 24.98 & 19 & 30 \\
\hline 0.30 & & & & & 35 & 12.6 & 100 & 5 & 17.60 & 13 & 23 \\
\hline 0.15 & & & & & 11 & 3.96 & 97 & 4.85 & 08.81 & 7.0 & 15 \\
\hline 0.075 & & & & & 4 & 1.44 & 68 & 3.4 & 04.84 & 3.0 & 8 \\
\hline
\end{tabular}

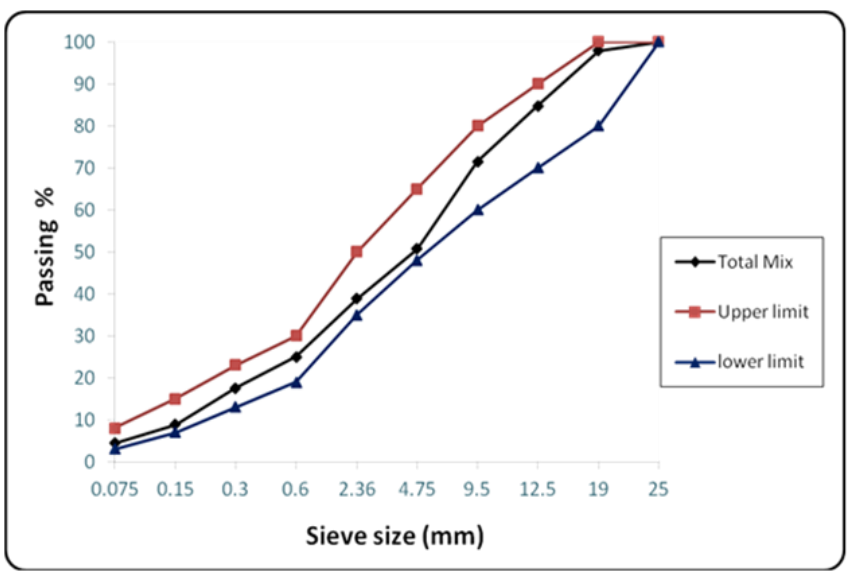

\subsection{Bitumen}

Road surfaces are very widely produced in the form of asphalt or a mixture of bitumen with aggregates,. The used bitumen in all asphalt concrete mixtures in this research paper was $60 / 70$ pentation grade. The properties of the used bitumen including penetration, kinematics viscosity, ring and ball softening point, specific gravity and flash point are shown in Table (3).

Figure 1 : Gradation of the Total Mix and Specification

Table 3: Properties of the used Bitumen.

\begin{tabular}{|l|l|l|}
\hline Test & Results & Specification Limits \\
\hline Specific Gravity & 1.05 & $1.0 \sim 1.1$ \\
\hline Penetration $\left(\right.$ at $\left.25^{\circ} \mathrm{C}\right), 0.1 \mathrm{~mm}$ & 65 & $60 \sim 70$ \\
\hline Softening Point, ${ }^{\circ} \mathrm{C}$ & 47 & $45 \sim 55$ \\
\hline Flash Point, ${ }^{\circ} \mathrm{C}$ & 266 & $\geq 250$ \\
\hline Kinematic Viscosity.(at $\left.135^{\circ} \mathrm{C}\right)$, Cst & 330 & $\geq 320$ \\
\hline
\end{tabular}

\subsection{Mixture Design}

Marshall Method of mix design which is the most popular mixture design method was used within this research. Asphalt concrete mix design methods attempt to balance the composition of aggregate and asphalt binder to achieve long lasting performance in a pavement structure. The main purpose of a mix design is to produce mixtures with high resistance to deformation and cracking. In addition, for the wearing surface, it is also necessary to provide surface texture and skid resistance. The properties of the produced mixtures depend on the physical and chemical properties of the used materials. Each of the component materials needs to be carefully selected and controlled to ensure that they are of a suitable quality for the asphalt mixtures and the expected performance. 
After batching, the aggregates were placed in an oven at $175^{\circ} \mathrm{C}$ for 2 hours. Approximately 1 hour before blending of the aggregate with bitumen, the bitumen is placed in the oven at $165^{\circ} \mathrm{C}$. After the aggregates and the asphalt were heated in the oven, trial specimens were prepared in laboratory at five different asphalt contents, with three specimens for each content. To achieve appropriate uniform mixing temperature, the specimens are then marked and stored over night for stability and flow measurements. Before the stability and flow tests were performed the specimens were kept in water bath at $60^{\circ} \mathrm{C}$ for 30 minutes.
Physical volumetric properties are commonly used when designing asphalt concrete. Appropriate VMA is required to provide space in the mix for enough asphalt cement to achieve proper aggregate coating and bonding, as well as to leave air voids for the thermal expansion of asphalt cement during high in-service temperatures. VMA in a compacted asphalt concrete has two components: the volume of voids that is filled with asphalt cement, and remaining voids filled with air. The average results of the volumetric properties of the Marshall specimens as well as their stability and flow test for the five selected asphalt contents are shown in table (4).

Table 4 : Mixture Design Results.

\begin{tabular}{|l|l|l|l|l|l|}
\hline \multirow{2}{*}{} & \multicolumn{5}{|l|}{$\%$ Bitumen Content } \\
\cline { 2 - 6 } & $4 \%$ & $4.5 \%$ & $5 \%$ & $5.5 \%$ & $6 \%$ \\
\hline Unit Weight (t/m3) & 2.25 & 2.29 & 2.34 & 2.28 & 2.24 \\
\hline$\% \mathrm{Vv}$ & 8.43 & 6.76 & 4.44 & 3.61 & 3.12 \\
\hline$\%$ VFB & 54.00 & 66.30 & 77.40 & 82.50 & 87.60 \\
\hline Marshall satiability (Kg) & 649 & 715 & 758 & 679 & 596 \\
\hline Marshall Flow (.01 in) & 8.0 & 10.0 & 13.0 & 15.0 & 17.0 \\
\hline
\end{tabular}

From the test property curves, plotted as described above and general note are outline:

- The satiability value increase with the increase of asphalt content up to a maximum and then start to decrease again.

- The flow value increases with increase of asphalt content.

- The curve of unit weight for total mix is similar to the stability curve.

- The percentage of air voids in total mix decrease with increase of asphalt content

- The percentage of aggregate voids filled with asphalt increase with the increase of asphalt content.

The optimum binder content (5\%) is selected as the average bitumen Content for maximum stability, maximum unit weight, and specified percent air voids in the total mix $(4 \%)$.. Later different percentages of the coarse natural aggregate were replaced by recycled crushed concrete aggregate and the optimum binder content was obtained for each replacement percentage. The used replacement percentages namely $10 \%, 20 \%, 30 \%, 40 \%$ and $50 \%$. of the natural aggregate.

\section{RESULTS AND DISCUSSION}

The measurement of the bulk specific gravity of compacted asphalt concrete mixtures is the basis for volumetric mix design and quality process control procedures [11]. It is clear from figure (2) that increasing of the recycled aggregate replacement ratio resulting decreasing in specific gravity for asphalt concrete mixtures. Lower specific gravity for asphalt concrete mixtures is due to lower specific gravity for the used recycled aggregate and also may be due to higher voids in the total mixtures. This result can be helpful to choose the optimum recycled aggregate replacement ratio.

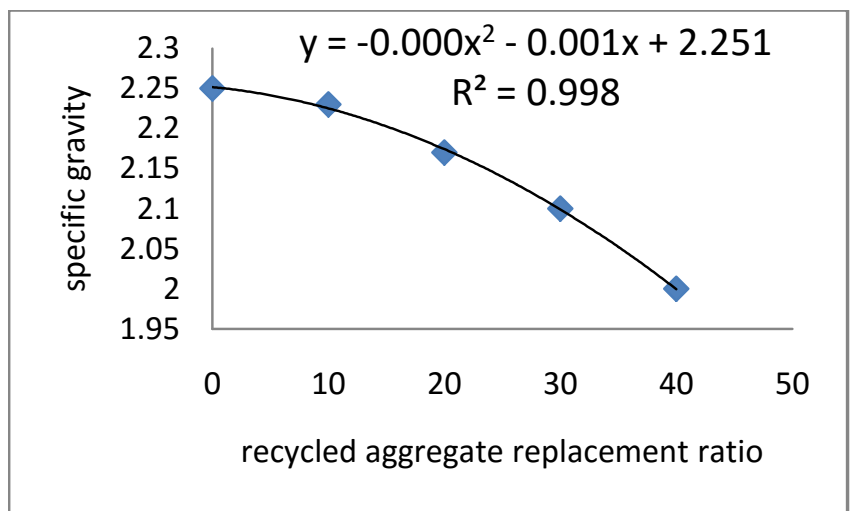

Figure 2: Relationship between recycled aggregate replacement ratio and asphalt concrete mixtures specific gravity

Bitumen content depends on the quality of aggregates used and the degree of absorption and the smoothness of gradation mixture. The function of bitumen in the asphalt mixture is to link the aggregate mixture of molecules with each other to become one block contiguous and cohesive, after mixing and compaction. Figure (3) represent the relation between recycled aggregate replacement ratio and bitumen content. By increasing the recycled aggregate replacement ratio the optimum bitumen content increase. This isdue to high absorption of recycled aggregate to bitumen and also cement film absorb some amount of bitumen. 


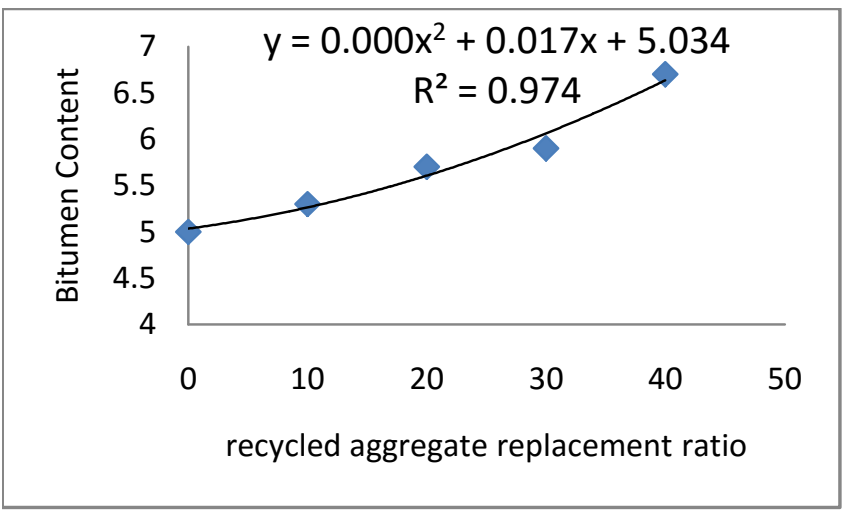

Figure 3: Relationship between recycled aggregate replacement ratio and the optimum bitumen content

Air voids are air that occurs between the coated aggregate particles in the final compacted asphalt concrete mixtures. Figure (3) shows that with the increase of recycled aggregate replacement ratio the air voids increase. The mixtures with high recycled aggregate replacement ratio have lower density because it has a higher air void that means the durability of an asphalt pavement is a function of the air-void content.

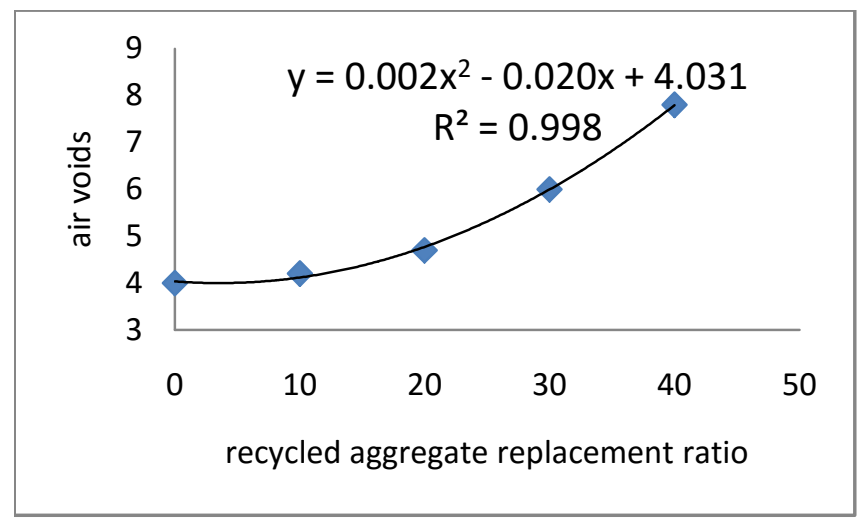

Figure 4: Relationship between recycled aggregate replacement ratio and air voids

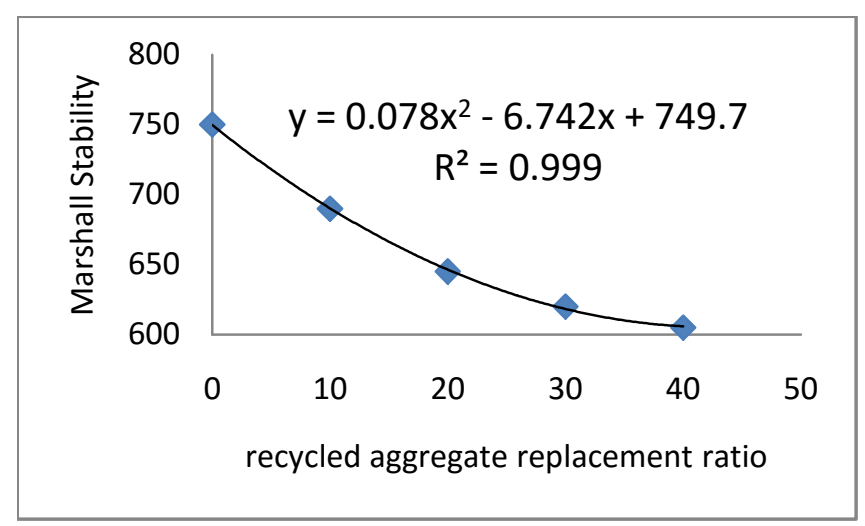

Figure 5: Relationship between recycled aggregate replacement ratio and Marshall stability

On the other hand the Marshall Stability decrease with increase of recycled aggregate replacement ratio because of the recycled aggregate is weak aggregate. The aggregate that used in cement concrete for long time lose some of it main properties and affects with weather condition and chemical factors from cement and atmosphere.

The mechanical performance of asphalt concrete mixtures can be evaluated using Marshall Stiffness (MS). It is considered a combined index that reflects both stability and plastic flow characteristics of the mixtures [12,13].

Marshall Stiffness can be calculated using equation number (1). The result of Marshall stiffness tabulated in table (5) and the results shows with the increase of recycled aggregate replacement ratio the Marshall stiffness decrease.

$\mathrm{MS}=\mathrm{S} /(\mathrm{F} \times \mathrm{t})$ Equation (1)

Where:

MS = Marshall Stiffness,

$\mathrm{S}=$ Marshall Stability,

$\mathrm{F}=$ Marshall Flow,

and $\mathrm{T}=$ specimen's thickness.

Table (5) Marshall Stiffness for asphalt concrete mixtures

\begin{tabular}{|l|l|l|l|}
\hline $\begin{array}{l}\text { Recycled } \\
\text { Aggregate } \\
\text { Replacement } \\
\text { Ratio }\end{array}$ & $\begin{array}{l}\text { Flow } \\
(0.1 \mathrm{~mm})\end{array}$ & $\begin{array}{l}\text { Stability } \\
(\mathrm{N})\end{array}$ & $\begin{array}{l}\text { Marshall } \\
\text { Stiffness } \\
(\mathrm{psi})\end{array}$ \\
\hline $0 \%$ & 13 & 750 & 9130 \\
\hline $10 \%$ & 15 & 690 & 8734 \\
\hline $20 \%$ & 16 & 645 & 7639 \\
\hline $30 \%$ & 20 & 620 & 6357 \\
\hline $40 \%$ & 23 & 605 & 6200 \\
\hline $50 \%$ & 27 & 595 & 5982 \\
\hline
\end{tabular}

The indirect tensile strength test was developed for use in testing cylindrical concrete specimens through the application of a compression load along a diametrical plane through two opposite loading head. This type of loading produces relatively uniform stress acting perpendicular to the applied load plane, causing the specimen to fail by splitting along the loaded plane [14-17].Figure (6) present the relation between indirect tensile strength and recycled aggregate replacement ratio. The indirect tensile strength (ITS) for each sample was calculated using equation number (2),

$\operatorname{ITS}=\frac{2 \mathrm{P}}{\pi \mathrm{td}}$

Where $\mathrm{P}$ is failure load, $\mathrm{t}$ is sample thickness, and $\mathrm{d}$ is sample diameter. It is clear that with increase of recycled aggregate replacement ratio the indirect tensile decrease because of the bitumen content increased in the mixtures and the mixtures can't resist the tensile loads. 


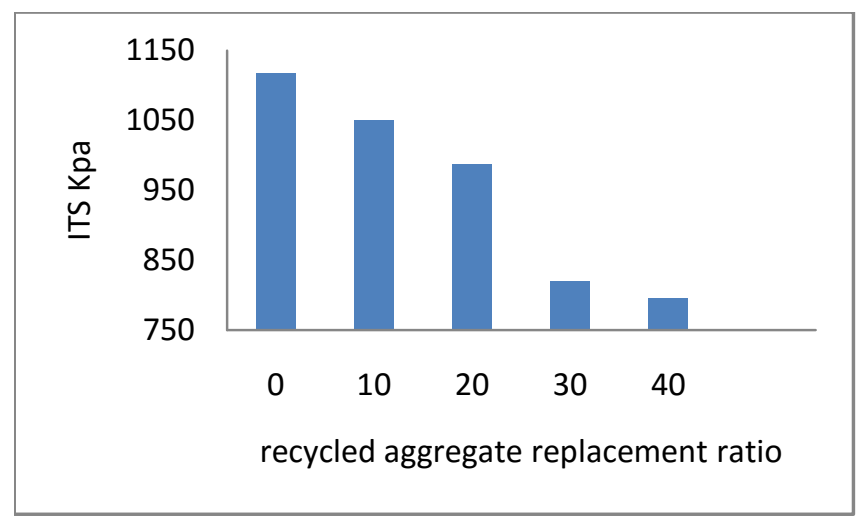

Figure 6: Relationship between recycled aggregate replacement ratio and the indirect tensile strength

\section{CONCLUSIONS}

The results of the research can be summarized as:-

1. Using recycled of crushed concrete aggregate in asphalt mixtures Sounds good from different point of view Environmental considerations, Economic factors and solving the problem of lack of materials.

2. Up to $20 \%$ of recycled of crushed concrete aggregate can be used in asphalt concrete mixtures.

3. The mixtures with recycled of crushed concrete aggregate have low stiffens and stability so it should be used at low traffic area.

4. Using recycled of crushed concrete aggregate in asphalt concrete mixtures can be assumed to be green solution for crushed concrete.

5. Recycled aggregate decrease the cost of highway construction and the energy needed for getting natural aggregate.

\section{ACKNOWLEDGEMENT}

The author sincerely thank Qena faculty of engineering south valley university for providing all needed research facilities.

\section{REFERENCES}

[1]. Mehta, P. K., "Reducing the Environmental Impact of Concrete," Concrete International, V. 23, No. 10, Oct. 2001, pp. 61-66.

[2]. Oikonomou, Nik D. "Recycled concrete aggregates." Cement and concrete composites 27.2 (2005): 315-318.

[3]. 3- Hopwood, Bill, Mary Mellor, and Geoff O'Brien. "Sustainable development: mapping different approaches." Sustainable development 13.1 (2005): 3852.

[4]. Paranavithana, Sumeda, and Abbas Mohajerani. "Effects of recycled concrete aggregates on properties of asphalt concrete." Resources, Conservation and Recycling 48.1 (2006): 1-12.

[5]. Tam, Vivian WY, et al. "Physio-chemical reactions in recycle aggregate concrete." Journal of hazardous materials 163.2 (2009): 823-828.
[6]. Daniel, Jo, and Aaron Lachance. "Mechanistic and volumetric properties of asphalt mixtures with recycled asphalt pavement." Transportation Research Record: Journal of the Transportation Research Board 1929 (2005): 28-36.

[7]. Wong, YiikDiew, Darren Delai Sun, and Dickson Lai. "Value-added utilisation of recycled concrete in hotmix asphalt." Waste Management 27.2 (2007): 294301.

[8]. Mills-Beale, Julian, and Zhanping You. "The mechanical properties of asphalt mixtures with recycled concrete aggregates." Construction and Building Materials 24.3 (2010): 230-235.

[9]. Tu, Tsung-Yueh, Yuen-Yuen Chen, and Chao-Lung Hwang. "Properties of HPC with recycled aggregates." Cement and Concrete Research 36.5 (2006): 943-950.

[10].Buchanan, M. Shane. "An evaluation of selected methods for measuring the bulk specific gravity of compacted hot mix asphalt (HMA) mixes."Association of Asphalt Paving Technologists Proc. Vol. 69. 2000

[11].Chen, Meizhu, Juntao Lin, and Shaopeng Wu. "Potential of recycled fine aggregates powder as filler in asphalt mixture." Construction and Building Materials 25.10 (2011): 3909-3914.

[12].Pellinen, Terhi, and Matthew Witczak. "Use of stiffness of hot-mix asphalt as a simple performance test." Transportation Research Record: Journal of the Transportation Research Board 1789 (2002): 80-90.

[13]. Tayebali, Akhtarhusein A., Bor-wen Tsai, and Carl L. Monismith. Stiffness of asphalt-aggregate mixes. No. SHRP-A-388. Washington DC: Strategic Highway Research Program, National Research Council, 1994.

[14].Roque, Reynaldo, and William G. Buttlar. "The development of a measurement and analysis system to accurately determine asphalt concrete properties using the indirect tensile mode (with discussion)." Journal of the Association of Asphalt Paving Technologists 61 (1992).

[15].Kennedy, Thomas William. "Characterization of asphalt pavement materials using the indirect tensile test." Association of Asphalt Paving Technologists Proc. Vol. 46. 1977.

[16].Buttlar, William G., and Reynaldo Roque. "Development and evaluation of the strategic highway research program measurement and analysis system for indirect tensile testing at low temperatures." Transportation Research Record1454 (1994).

[17].Mohammad, Louay N., and Harold R. Paul. Evaluation of indirect tensile test for determining structural properties of asphalt mix. No. 1417. 1993. 


\section{BIOGRAPHIES}

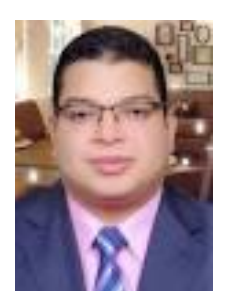

Dr. Eng. Farag Khodary Ph.D Pavement Engineering Materials, Technische Universität Darmstadt, Germany (2010). M.Sc.: Civil Engineering - Highway Materials (Southvalley University, 2005, Distinction 90.75\%), B.Sc.: Civil Engineering (south valley University, Aswan, Egypt, June 2000), "79.95\% Very Good with honourdaegree". 